\title{
Processos de Desenvolvimento Participativo de Tecnologias Digitais Educacionais nos Contextos Urbano e da Educação do Campo
}

\author{
Dyego Carlos Sales de Morais ${ }^{1}$, Taciana Pontual Falcão ${ }^{2}$, Flávia Mendes de \\ Andrade e Peres ${ }^{3}$, Patrícia Cabral de Azevedo Restelli Tedesco ${ }^{1}$ \\ ${ }^{1}$ Centro de Informática - Universidade Federal de Pernambuco - Recife, PE \\ ${ }^{2}$ Departamento de Computação - Universidade Federal Rural de Pernambuco - Recife, \\ $\mathrm{PE}$ \\ ${ }^{3}$ Departamento de Educação - Universidade Federal Rural de Pernambuco - Recife, PE \\ moraisdcsegmail.com, taciana.pontualeufrpe.br, \\ peres.flaviaegmail.com, pcartecin.ufpe.br
}

Abstract. This report presents participatory processes for the development of digital educational artifacts within the DEMULTS project. The settings were one urban school (where three cycles of action research were performed from 2011 to 2016), and three rural schools (with two cycles, from 2017 to 2020). The processes are based on Participatory Design, which enabled the creation of a democratic arrangement that culminated in an equity of power in the decisions about the artifacts being developed with elementary and high school students.

Resumo. Este relato apresenta processos de desenvolvimento participativo de artefatos digitais educacionais construídos no âmbito do projeto DEMULTS em uma escola no contexto urbano ao longo de três ciclos de pesquisa-ação (20112016), e em três escolas da Educação do Campo durante dois ciclos (20172020). Os processos têm como base a metodologia do Design Participativo, possibilitando a construção de um arranjo democrático que culminou numa equidade de poder nas decisões sobre os artefatos construídos com estudantes do ensino fundamental e médio.

\section{Introdução}

$\mathrm{Na}$ Base Nacional Comum Curricular (BNCC) consta que, além de acesso e compartilhamento de informações para compreensão e uso de tecnologias digitais, é preciso que estudantes sejam capazes de construir tais tecnologias "de forma crítica, significativa, reflexiva e ética nas diversas práticas sociais (incluindo as escolares) para (...) produzir conhecimentos, resolver problemas e exercer protagonismo e autoria na vida pessoal e coletiva" [Brasil 2017]. No entanto, apesar de haver, no contexto urbano, um número crescente de trabalhos que fomentam o desenvolvimento dessa competência, nos contextos rurais ainda há poucos trabalhos que apresentam propostas além do uso de tecnologias digitais, contemplando o processo de desenvolvimento desses artefatos [Ortiz \& Pereira 2019]. No contexto da Educação do Campo (EdC), muitos trabalhos discutem inclusão digital, porém sem abordar o desenvolvimento de tecnologias com estudantes [Munarim 2014; Santos \& Leão 2017]. 
A EdC surge a partir da luta camponesa por um modelo de educação não apenas situado na zona rural, mas convergente com as problemáticas características de contextos campesinos, garantindo condições que não requeiram migração a centros urbanos para se ter acesso a educação, ciência e tecnologia, e que leve em consideração a história do território e a participação dos sujeitos campesinos [Caldart 2012]. Sendo assim, o desenvolvimento de tecnologias digitais no contexto da EdC necessita partir do território em que a escola está, fomentando a participação dos sujeitos nos espaços escolares [Munarim 2014] - o que converge com métodos de desenvolvimento de artefatos que destacam a participação de usuários finais, como o Design Participativo (DP) [Spinuzzi 2002]. Ainda assim, há de se ter cuidado para não reproduzir um modelo centralizador, apenas extraindo informações de usuários [Amstel 2009], e sim fomentar a participação genuína, com equidade de poder decisório.

Visando contribuir para preencher a lacuna percebida na EdC em relação ao desenvolvimento crítico de tecnologias na escola proposto pela BNCC, o projeto DEMULTS (Desenvolvimento Educacional de Multimídias Sustentáveis) teve seu processo de desenvolvimento participativo de tecnologias digitais educacionais (até então realizado em contextos urbanos [Morais \& Falcão 2019]) adaptado para o DEMULTSCampo. Neste relato, são apresentadas as mudanças no processo DEMULTS entre os ciclos de pesquisa-ação do contexto urbano para a EdC. O presente relato está organizado em quatro seções, além desta: primeiro, apresenta-se o conceito de EdC e suas demandas; em seguida, são apresentadas abordagens de design e desenvolvimento de tecnologias digitais, em especial o DP como uma alternativa para o contexto escolar campesino; então, é apresentada a metodologia do projeto DEMULTS, os contextos e as mudanças dos ciclos urbanos para os de EdC; por fim, são feitas considerações finais e oportunidades de trabalhos futuros.

\section{Educação do Campo}

A Educação do Campo (EdC) é um modelo educacional protagonizado por trabalhadores, movimentos sociais e organizações do campo, que reivindicam o direito à educação formal no local onde estão inseridos e com a cultura e os valores que lhes formam enquanto sujeitos do campo. Assim, a EdC é construída entrelaçando saberes científicos aos saberes advindos de experiências do trabalho, da cultura e das lutas sociais dos camponeses [Caldart 2012]. A EdC fortalece o vínculo histórico das famílias do campo engajadas na luta por reforma agrária, com um projeto societário emancipatório, pautado na liberdade, justiça social, autonomia e participação dos sujeitos do campo.

Dada a necessidade de políticas públicas que garantam educação escolar fundamentada nesses ideais [Caldart 2012], foram reivindicados para $\mathrm{EdC}$ materiais contextualizados e construídos com os sujeitos do campo. Em 2013, surgiu o Programa Nacional do Livro Didático para EdC, com o objetivo de produção e distribuição de livros contextualizados para o território campesino. No entanto, o programa, extinto em 2018, abrangia apenas os anos iniciais do Ensino Fundamental, com livros feitos por grandes editoras sem participação dos sujeitos do campo e conteúdos insuficientemente contextualizados para a vida no campo [Molina 2014].

Dessa forma, a luta pela garantia de uma educação pensada e construída com os povos do campo permanece; e, com o avanço das tecnologias digitais, apresenta desafios particulares relacionados à construção, e não apenas o uso, de artefatos didáticos digitais 
em parceria com estudantes e professores de escolas do campo. Nesse sentido, foi preciso decidir qual processo de desenvolvimento melhor se adequaria ao contexto escolar do campo. Apresentam-se a seguir processos de desenvolvimento de tecnologias digitais consolidados na área de Interação Humano-Computador, que inserem o usuário final em diferentes níveis de participação.

\section{Abordagens Participativas de Desenvolvimento de Tecnologias Digitais}

Inserir usuários no desenvolvimento de software tem se mostrado interessante para alcançar uma boa experiência de uso dos produtos [Amstel 2009], por, potencialmente, melhor contemplar preferências e necessidades [Spinuzzi 2005]. Considera-se que o usuário final possui um domínio sobre a prática em que se pretende intervir com um artefato tecnológico, que o designer não necessariamente possui. Faz-se, portanto, necessário que o usuário explique e/ou seja observado em sua prática para que o designer aprenda e consiga projetar. No contex to educacional, há uma problemática particular, pois os usuários, sendo estudantes em formação, podem não possuir domínio sobre o problema, sendo necessária a participação de outras pessoas que possuam tal domínio, como educadores e pesquisadores.

O Design Centrado no Usuário (DCU) é uma das abordagens mais usadas para inserir usuários finais em processos desenvolvimento de artefatos digitais. No DCU os usuários são consultados para idealizar e/ou validar artefatos, no entanto sem lhes permitir poder sobre as decisões que são implementadas no produto final [Spinuzzi 2002; Amstel 2009]. O DCU não possui intencionalidade emancipatória [Amstel 2009], e mantém os papéis de produtores e consumidores como grupos separados, fortalecendo a ideia do designer como um "herói" e o usuário como um sujeito incapaz de tomar decisões [Spinuzzi 2002]. Tal noção termina por inferiorizar o potencial dos usuários e não coaduna com os interesses da EdC.

Já o Design Participativo (DP) é uma abordagem que se aproxima mais da intencionalidade emancipatória da $\mathrm{EdC}$, com técnicas que promovem colaboração, diálogo e troca de conhecimento entre projetistas e representantes do público-alvo [Muller e Druin 2010], como brainstorming, braindrawing e storyboarding. No entanto, não se trata apenas de aplicar técnicas ou inserir usuários no processo de forma consultiva, mas possibilitar um arranjo dialógico que promova aprendizagem mútua entre todos os participantes durante todo o processo [Muller e Druin 2010]. Por meio do DP, abrem-se oportunidades de vivência participativa na construção de artefatos tecnológicos digitais, que dialogam com a necessidade da EdC e se alinham com abordagens de pesquisa-ação.

\section{Processos DEMULTS}

O presente relato refere-se a processos gerados a partir de ciclos de pesquisa-ação executados no âmbito do projeto DEMULTS, realizados em uma escola no perímetro urbano (2001-2016) e três escolas situadas em zonas rurais, que buscam seguir diretrizes da EdC (2017-2020). O DEMULTS se baseia na metodologia democrática do Design Participativo, com ênfase na aprendizagem decorrente da vivência em situações práticas, por meio da interação entre estudantes e colaboradores do projeto, em que todos constroem conhecimentos inerentes ao desenvolvimento de artefatos didáticos digitais, bem como saberes do território campesino ou dos conteúdos curriculares. 
A coleta de dados se dá por meio de observação participante, a partir dos ciclos de pesquisa-ação do DEMULTS, que duram em torno de um ano, nos quais estudantes desenvolvem artefatos digitais educacionais (jogos digitais e aplicativos) com colaboradores e pesquisadores do projeto. A pesquisa-ação, por ser emergente e iterativa [Merriam \& Tisdell 2015], possibilita que o processo do DEMULTS seja maturado a cada ciclo de ação, descrição, avaliação e planejamento da pesquisa [Tripp 2005], promovendo aprendizagem para todos os participantes, incluindo pesquisadores e colaboradores, tanto a respeito da prática investigada, quanto da própria investigação.

A equipe do DEMULTS conta com pesquisadores colaboradores; bolsistas de iniciação científica e voluntários (estudantes de graduação de cursos que contemplem os conteúdos de cada ciclo; e nas áreas de design e computação). Todos os estudantes voluntários têm sua participação formalmente autorizada pelos responsáveis legais, através de um termo de consentimento. Os processos construídos durante os ciclos em contextos urbano e da EdC estão descritos a seguir.

\subsection{Contexto 1: Escola Urbana}

O primeiro contexto em que se aplicou o projeto DEMULTS foi em uma escola estadual de referência em ensino médio (EREM), na região metropolitana de Recife, Pernambuco, zona urbana. Esta escola possuía atividades em tempo integral, sendo dois turnos na semana reservados para atividades extra-curriculares, das quais todos os estudantes da escola participavam. O DEMULTS era um dos projetos parceiros para realização dessas atividades e foi aplicado, tendo seu processo maturado, nessa escola, durante três ciclos, entre 2011 e 2016, com estudantes de primeiro e segundo anos do Ensino Médio. Os jogos digitais educacionais desenvolvidos foram referentes a conteúdos de História e Biologia, no primeiro ciclo (2011-2012), com nove estudantes; Química, no segundo ciclo (20132014), com 17 estudantes; e Português e Matemática, no terceiro ciclo (2015-2016) com 19 estudantes. Os ciclos sempre contam com pesquisadores no suporte das disciplinas, mas no segundo ciclo (2013-2014) teve também a participação de uma docente da escola, professora de Química.

O processo de desenvolvimento de jogos digitais educacionais do DEMULTS em contexto urbano foi iterativamente melhorado a cada ciclo. Desde o primeiro ciclo, os estudantes propuseram alterações durante a execução do projeto. É exemplo disso a mudança de construção do Game Design Document (GDD), um documento percebido pelos estudantes e pela equipe do DEMULTS como de difícil legibilidade e manutenção, para o uso de histórias em quadrinhos para documentar os requisitos dos jogos (storyboards) [Morais et al. 2015]. Essa alteração nos artefatos que mediaram o processo demonstra o diálogo entre estudantes, pesquisadores e colaboradores para a melhoria contínua do projeto possibilitada pelo Design Participativo com a pesquisa-ação.

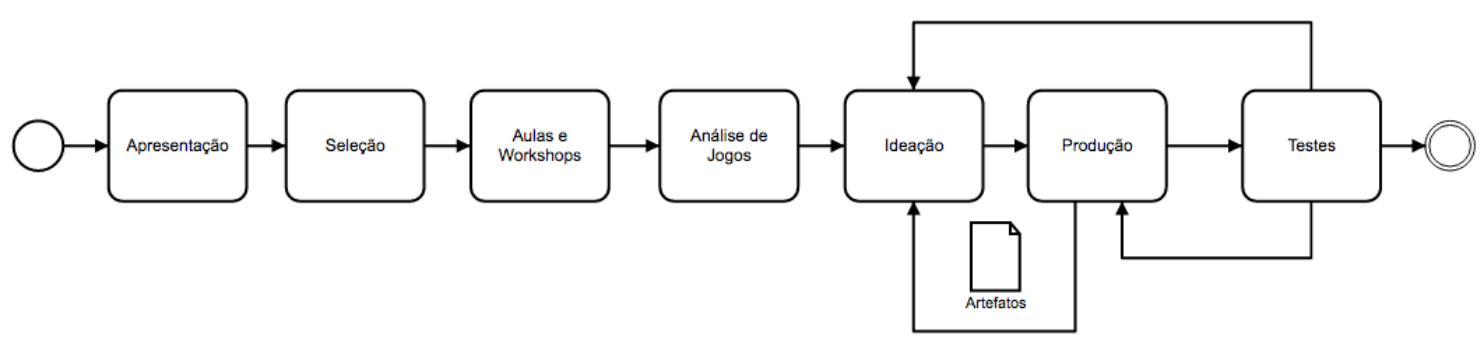

Figura 1. Etapas do processo de desenvolvimento de jogos no contexto escolar. 
O processo resultante dos três ciclos no contexto urbano construído coletivamente com estudantes, colaboradores e pesquisadores do DEMULTS, possui as seguintes etapas (ilustradas na Figura 1):

- Apresentação e Seleção, nas quais se faz uma exposição da proposta do projeto seguida de aplicação de formulário para seleção dos estudantes, seguindo critérios de conhecimento prévio e interesse por tecnologia, jogos, desenho, e disciplinas específicas que são exploradas nos artefatos didáticos digitais do ciclo.

- Aulas e Workshops, em que há práticas criativas para identificar perfis dos estudantes nas equipes, e observar o trabalho colaborativo; aulas (para todos os estudantes) de introdução a lógica de programação; game design, com conceituação de jogos, narrativas, mecânicas, personagens e regras; e customização de elementos visuais, como cenários, obstáculos e animações de personagens, dentro do ambiente de programação; e aulas específicas para cada perfil de estudantes (designers e programadores) de desenho à mão livre e digital na ferramenta de ilustração, e de programação em blocos no ambiente de programação, respectivamente.

- Análise de Jogos, que se tornou uma etapa em si apenas a partir do segundo ciclo, para possibilitar que os estudantes avaliem jogos aplicando os conceitos que aprenderam nos workshops.

- Ideação, em que é feito um brainstorm, no qual os estudantes se dividem em grupos e trabalham colaborativamente com prazos bem definidos para construir a proposta de jogo (narrativa e adequação dos conteúdos curriculares), seguida de uma votação para discutirem qual das ideias propostas se torna oficial, ou se eles têm condições de unir as propostas.

- Produção, em que as artes são criadas pelos designers e integradas aos jogos, que são desenvolvidos pelos programadores, por meio de integração de componentes programados por terceiros ou programados com blocos por eles mesmos; algumas vezes sendo necessário adaptar as histórias idealizadas, para dar continuidade ao processo.

- Testes, em que, visando uma validação, bem como possíveis melhorias, são realizados testes informais dos jogos, nos quais os usuários (estudantes da mesma escola, mas que não participaram do projeto) falam o que pensam no momento do uso do jogo.

Este processo foi construído na especificidade do contexto escolar urbano para o desenvolvimento de cinco jogos digitais educacionais (no Stencyl), ao longo de três ciclos, sendo este apresentado aqui o executado no último ciclo. A aplicação do Design Participativo se mostrou promissora, pois evidenciou as atividades do projeto como um espaço simbólico de construção de vínculos sociais descentralizados, com hierarquia horizontal, gerando sentido de pertencimento e participação [Peres, Oliveira, Morais 2017]. Os estudantes não apenas eram consultados, mas projetavam e construíam os artefatos com o mesmo poder de voz dos colaboradores e pesquisadores do DEMULTS.

Perceberam-se também, na execução do último ciclo, pontos de melhorias: (i) a apresentação poderia ser mais dinâmica, de modo a gerar curiosidade, sem deixar de envolver os estudantes na construção do projeto; (ii) os conteúdos vistos previamente em aulas e workshops eram comumente esquecidos no momento da produção, podendo serem abordados com ainda mais participação dos estudantes no momento de necessidade da aplicação no design ou programação do jogo [Morais \& Falcão 2019]; (iii) a disciplina 
curricular era pré-definida, não havendo possibilidade de escolha para os estudantes, o que se entende que pode gerar frustração ou desinteresse pelo projeto, visto que muitos estudantes se interessam no primeiro momento com a possibilidade de criar jogos digitais, mas durante o processo percebem que é preciso estudar bastante os conteúdos curriculares abordados nos artefatos didáticos que estão desenvolvendo; e (iv) os estudantes sempre perguntavam quem seriam os usuários dos jogos que estavam desenvolvendo, ao passo que não se tinha uma parceria firmada com outra instituição e eles não conheciam o usuário pressuposto até alguns colegas da mesma escola externos ao projeto testarem seus jogos.

\subsection{Contexto 2: Escolas do Campo}

No contexto de Educação do Campo, o DEMULTS-Campo foi aplicado em três escolas ao longo de dois ciclos: uma escola no primeiro ciclo (2017-2018) e duas no segundo ciclo (2019-2020). No primeiro ciclo, a escola campo se localizava em Chã da Mangabeira, comunidade do município de Paulista, que fica na região metropolitana de Recife, Pernambuco. Foi selecionada a partir de reuniões com responsáveis pela Gerência de Políticas Educacionais da EdC (GEPEC) da Secretaria de Educação do Estado de Pernambuco (SEDUC-PE), levando em consideração escolas que haviam passado por formações para migrarem para o modelo de EdC. Embora a escola estivesse localizada em uma área com características rurais, não havia ainda trabalhos que visassem o fortalecimento da $\mathrm{EdC}$ com os estudantes, como o cultivo de horta orgânica ou a criação de uma composteira. Neste ciclo, foi desenvolvido um jogo digital com conteúdos referentes a Química e sustentabilidade com inicialmente 25 estudantes de Ensino Médio, do primeiro ao terceiro ano. Um professor de Química, externo ao projeto e à escola, assumiu o papel de cliente e sugeriu algumas temáticas com conteúdos considerados de difícil contextualização com o cotidiano dos estudantes.

As duas escolas em que foi realizado o segundo ciclo ficam localizadas no município de Vicência, Zona da Mata Norte de Pernambuco, e foram selecionadas a partir de reuniões de pesquisadoras do DEMULTS e da UFRPE com responsáveis pela Secretaria de Educação do Município de Vicência, levando em consideração escolas próximas a rodovias para possibilitar aplicação de um único ciclo simultâneo em duas escolas, bem como estarem mais avançadas que as do primeiro ciclo do DEMULTSCampo no processo de se adequarem às diretrizes de EdC. A cidade de Vicência tem vínculo histórico com o corte de cana-de-açúcar, de modo que até hoje a cidade é circundada de terrenos de plantio de cana. As escolas campo deste ciclo ficam dentro de terrenos de usinas (uma desativada e outra ativada). Neste ciclo, 50 estudantes de Ensino Fundamental II (do sexto ao nono ano) participaram do desenvolvimento de cinco jogos digitais e um aplicativo com conteúdos referentes ao tema da sustentabilidade. Em ambas as escolas, neste segundo ciclo, houve participação de técnicos em agroecologia, que já faziam visitas pedagógicas regulares às escolas trabalhando com compostagem e hortas orgânicas com os estudantes. Esses técnicos são formados pelo Serviço de Tecnologia Alternativa (SERTA), organização de referência na promoção do desenvolvimento sustentável e fortalecimento da agricultura familiar. Por meio da parceria com a Secretaria de Educação de Vicência, o trabalho dos técnicos na escola objetiva uma maior aproximação às diretrizes da $\mathrm{EdC}$. 
Em comparação ao contexto urbano, em que o processo do DEMULTS já havia sido baseado no Design Participativo, o contexto de Educação do Campo exige ainda mais participação e troca de saberes entre todos os participantes, com arranjos democráticos e horizontalidade nas decisões, inclusive, gerando para os pesquisadores aprendizagem sobre a cultura, as práticas e os valores campesinos.

A partir dos pontos de melhorias identificados no contexto urbano, e das especificidades do campo, as principais alterações no processo DEMULTS para o contexto da EdC foram: (i) a apresentação mais participativa com uma roda de diálogo e dinâmica de grupo; (ii) aulas ou workshops mais curtos, apenas introdutórios aos ambientes de design e desenvolvimento de jogos e aplicativos, com uma antecipação das etapas de ideação e produção, o que gerou uma abordagem mais próxima da prototipação em cooperação entre usuários e designers proposta pelo Design Participativo [Bødker 1991]; (iii) a inserção da etapa de imersão, na qual os participantes se envolvem em situações práticas para produção de sentidos sobre os conteúdos necessários para desenvolvimento do artefato didático digital e realizam pesquisas para que tanto os estudantes quanto os pesquisadores entendam mais sobre a história do território e dos participantes; e (iv) a definição de que estudantes de outras escolas do campo seriam os usuários dos artefatos, a partir das parcerias firmadas com o professor "cliente" e com a Secretaria de Educação de Vicência.

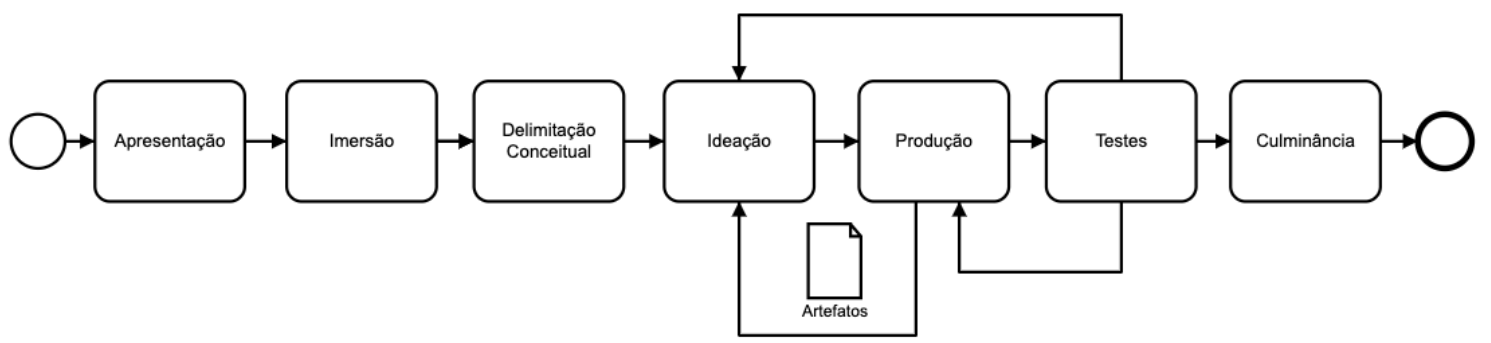

Figura 2. Etapas do processo de desenvolvimento de artefatos didáticos digitais na EdC.

A seleção dos estudantes, no contexto específico das escolas do último ciclo em que o DEMULTS-Campo foi realizado, se deu a partir de contato com as coordenadoras das escolas, que precisavam saber quais seriam os estudantes participantes antes do início do projeto, pois, como as atividades ocorreriam no contraturno (em horário em que os estudantes normalmente não estariam na escola), era necessário solicitar merendas e comunicar aos responsáveis. As coordenadoras indicaram estudantes do $6^{\circ}$ ao $9^{\circ}$ ano do Ensino Fundamental, com diversidade de gênero, de diversos territórios do campo e variados rendimentos escolares e comportamentos com vários níveis de compatibilidade com as regras de funcionamento do ambiente escolar. O processo, resultante dos dois ciclos no contexto de EdC, possui as seguintes etapas (exibidas na Figura 2):

- Apresentação, em que é feita uma roda de diálogo para apresentar o projeto e saber o que os estudantes esperam aprender durante o processo; seguida por uma dinâmica de grupo para apresentação de cada participante; e um braindraw sobre tecnologia no cotidiano dos estudantes (técnica participativa, tal qual o brainstorm, mas usando desenhos).

- Imersão, em que, com o objetivo de irem se familiarizando com elementos de jogos como roteiro, narrativa, mecânica, regras, desafios e recompensas, os estudantes, separando-se em grupos, produzem uma história em quadrinhos sobre aspectos do seu cotidiano, como se eles fossem o personagem principal de um 
jogo. Além disso, nessa etapa, com o objetivo de conhecer o contexto do território e da história de vida dos estudantes e de seus familiares, constrói-se com eles um um roteiro de entrevistas, para que realizem com seus pais ou responsáveis.

- Delimitação conceitual, em que se realiza um brainstorm sobre a relação entre os aspectos do cotidiano dos estudantes identificados na etapa de imersão com temáticas ou práticas que fortalecem a EdC. Essa interseção delimita os conceitos e práticas campesinas que serão abordados nos artefatos digitais didáticos nas próximas etapas.

- Ideação, em que, a partir de pesquisas com o apoio de colaboradores experientes na temática do recurso didático, define-se o roteiro e a narrativa dos artefatos com novas histórias em quadrinhos.

- Produção, em que, com a narrativa definida, parte-se para o desenvolvimento dos artefatos didáticos digitais, utilizando as ferramentas de design e programação, similar ao que ocorre no processo do contex to urbano.

- Testes, em que os produtos são validados com outros estudantes, externos ao projeto, similar ao processo do contexto urbano.

- Culminância, em que os estudantes apresentam seus produtos para comunidade escolar, incluindo professores, gestores, mães, pais e responsáveis.

Este processo foi construído no contexto da EdC e por meio dele foram desenvolvidos um aplicativo Android (com AppInventor) e seis jogos educacionais (com Stencyl e Scratch) sobre reciclagem, compostagem, horta orgânica e agroecologia.

No primeiro ciclo de EdC, a definição de conteúdo ocorreu com a parceria de um professor de Química de outra escola que, assumindo o papel de "cliente", solicitou um jogo enumerando opções de temáticas oriundas de sua vivência de sala de aula, para que os estudantes escolhessem. A escolha é uma prática democrática do Design Participativo e os estudantes optaram por compostagem por possibilitar uma maior abrangência de conteúdos. Já no segundo ciclo, a definição de conteúdo ocorreu a partir dos saberes prévios trazidos pelos estudantes na imersão e na ideação, o que ampliou o horizonte participativo da simples escolha para a construção coletiva de conhecimento.

Além disso, por não se ter uma prática estabelecida de agroecologia na escola, no primeiro ciclo, foi construída uma composteira com os estudantes, o que fortalece o projeto de sociedade defendido pela EdC, com agroecologia e sustentabilidade, mas os estudantes não possuíam conhecimentos prévios sobre as práticas, reduzindo a troca de saberes. Enquanto que no segundo ciclo, graças à parceria da Secretaria de Educação de Vicência com o SERTA, os estudantes já possuíam saberes sobre práticas agroecológicas, de modo a possibilitar dar um passo a mais no fortalecimento da $\mathrm{EdC}$, com os estudantes realizando entrevistas com seus responsáveis para estabelecer um vínculo com sua ancestralidade e a historicidade do território que compõem. Tais entrevistas serviram também para que os pesquisadores e colaboradores aprendessem mais sobre o contexto em que estavam imergindo.

Entende-se que essas adaptações no processo do DEMULTS-Campo só foram possíveis devido à mudança intencional do contexto, em que se saiu de um ambiente com uma maior intersecção entre o urbano e o rural para um contexto mais campesino com experiências prévias dos estudantes, de modo a possibilitar troca de saberes, inclusive com aprendizagem para os pesquisadores. Além disso, a participação de técnicos em agroecologia que já desenvolviam atividades com estudantes antes do projeto foi de suma 
importância para reduzir a distância simbólica entre os saberes dos pesquisadores advindos de centros urbanos e dos estudantes campesinos.

Outro ponto de destaque é que a programação em blocos auxiliou o processo participativo de desenvolvimento por estudantes, já que não foi necessário lecionar previamente a eles os conceitos que seriam necessários para produção dos artefatos digitais nos ciclos de Educação do Campo. Ao invés disto, a produção ocorreu com colaboração e troca de saberes sobre demanda, ou seja, ao passo que os estudantes e técnicos ensinavam aos pesquisadores detalhes sobre práticas agroecológicas, os pesquisadores formavam uma equipe de programação com os estudantes e à medida que determinado conceito de programação era necessário (como variável, condicional e laço), o pesquisador ensinava ao estudante. $\mathrm{O}$ mesmo ocorria com as demandas de design.

Todas as alterações no processo foram realizadas visando uma maior aproximação às diretrizes da EdC por meio das práticas democráticas do Design Participativo. Tais mudanças fortaleceram o projeto de Educação do Campo, pois possibilitaram uma experiência genuinamente participativa de desenvolvimento de tecnologias digitais com estudantes de escolas do campo. Estudantes e técnicos reconheceram o potencial de troca de saberes, de modo que ao término, foi solicitado que eles fizessem perguntas aos pesquisadores e uma das perguntas foi: "O que aprenderam com os estudantes no projeto? Já que vieram nos ensinar, mas acabou sendo uma troca de conhecimento".

\section{Conclusões e Trabalhos Futuros}

Este trabalho apresentou os processos do grupo de pesquisa DEMULTS que executa ciclos de pesquisa-ação no contexto urbano e no contexto da EdC, sendo o DP um forte elemento constitutivo dos processos. Os processos apresentados apontam para uma necessidade de maior fomento à participação no contexto da $\mathrm{EdC}$, devido às diretrizes desse modelo educacional, que reivindica isso desde a gestão escolar até as práticas docentes e atividades extracurriculares. Nesse sentido, entende-se que o DP possibilitou que durante todo o processo de desenvolvimento de artefatos didáticos digitais, as vozes dos estudantes fossem consideradas como de equânime poder, e não apenas ouvidas por outros participantes com maior poder de decisão. Replicar os processos apresentados nesse trabalho em contextos similares, fazendo as adequações necessárias, pode gerar resultados promissores quanto à criação de um arranjo democrático onde estudantes, interagindo com colaboradores mais experientes em design e computação, se envolvem no desenvolvimento de artefatos didáticos digitais.

As dificuldades relacionadas aos processos apresentados são principalmente decorrentes da infraestrutura escolar em ambos os territórios (urbano e rural), mas com maior problemática para o segundo ciclo de EdC, pela falta de computadores nas escolas. Por isso, foi necessário ir a um centro de cursos numa área mais urbanizada da cidade. Entende-se a problemática que surge a partir disso, pois o fortalecimento da EdC perpassa por garantir acesso à educação, ciência e tecnologia no locus escolar situado em territórios campesinos. No entanto, tal limitação não impediu a realização, na própria escola, das etapas anteriores e posteriores à de produção.

Como trabalhos futuros, pretende-se analisar os níveis de participação dos estudantes por etapa, levando em consideração os possíveis aspectos que promovem a participação nas atividades do DEMULTS, como intervenções dos colaboradores, arranjo dialógico entre pares, interesse na resolução de problemas ou nos conteúdos abordados. 


\section{Referências}

Amstel, F. V. (2009) "Políticas de Participação no Design de Interação", In: Spinillo, C. G.; Farias, P. L. (Ed.). Anais do $4^{\circ}$ Congresso Internacional de Design da Informação $/ 3^{\circ}$ InfoDesign Brasil / $4^{\circ}$ Congic. Rio de Janeiro.

Brasil. (2017) Base Nacional Comum Curricular. Brasília: Ministério da Educação.

Bødker, S., \& Grønbæk, K. (1991) "Cooperative Prototyping: users and designers in mutual activity", In: International Journal of Man-Machine Studies, 34(3), 453-478.

Caldart, R. S. (2012) "Educação do Campo", In: Caldart, R. S.; Pereira, I. B.; Alentejano, P.; Frigotto, G. (Orgs.) Dicionário da EdC. Rio de Janeiro, São Paulo: Escola Politécnica de Saúde Joaquim Nabuco,Expressão Popular.

Peres, F. M. D. A., Oliveira, G. S., Morais, D. C. S. (2017) "Os Outros Ocultos nas Interfaces de Jogos Digitais Educacionais" In: Informática na Educação: Teoria \& Prática, 20 (3 set/dez).

Merriam, S. B., \& Tisdell, E. J. (2015) Qualitative research: A guide to design and implementation. John Wiley \& Sons.

Molina, M. C. (2014) "Políticas públicas em Educação do Campo: avanços e desafios do PNLD Campo", In: Livro Didático e Educação do Campo, Carvalho, G. T.; Martins, M. F. A, Belo Horizonte/MG, n. 85, p. 25 - 34.

Morais, D., Gomes, T., Souza, A., \& Peres, F. (2015, October). "Storyboards no Desenvolvimento de Jogos Digitais Educacionais por Usuários Finais: Um Relato de Experiência”. In: Simpósio Brasileiro de Informática na Educação (SBIE). 26, No. 1.

Morais, D. C. S., Rocha Falcão, T. P. (2019). "Abordagem Participativa de Desenvolvimento de Jogos Digitais Educacionais no Contexto Escolar", In: Revista Brasileira de Informática na Educação, 27(01), 132.

Muller, M. J., Druin, A. (2010) "Participatory Design: The Third Space in HCI", In: Human-Computer Interaction: Development Process. J. Jacko and A. Sears. Eds. Handbook of HCI.

Munarim, I. (2014) "As tecnologias digitais nas escolas do campo: contextos, desafios e possibilidades". Tese (Doutorado) — Universidade Federal de Santa Catarina (UFSC).

Ortiz, J. S. B.; Pereira, R. (2019) "Ten Years of Initiatives to Promote Computational Thinking: A Systematic Mapping of Literature", In: Journal on Computational Thinking (JCThink), v. 3, n. 1, p. 96, 2019.

Santos, S. F., \& Leão, M. F. (2017) "Uso de objetos educacionais digitais para ensinar sistemas do corpo humano em uma escola do campo", In: Revista Brasileira de Educação do Campo, 2(3), 861-880.

Spinuzzi, C. (2002) "A Scandinavian Challenge, a US Response: Methodological assumptions in Scandinavian and US prototyping approaches", In: Proceedings of the 20th Annual International Conference on Computer Documentation (pp. 208-215).

Spinuzzi, C. (2005). The methodology of participatory design. Technical ommunication.

Tripp, D. (2005). Pesquisa-ação: uma introdução metodológica. Educação e Pesquisa. 